\section{ORIGINAL RESEARCH}

\author{
A. Ehteshami Rad \\ M.T. Luetmer \\ M.H. Murad \\ D.F. Kallmes
}

\title{
The Association between the Duration of Preoperative Pain and Pain Improvement in Vertebral Augmentation: A Meta-Analysis
}

BACKGROUND AND PURPOSE: Most physicians consider length of preoperative pain as an important
factor to include patients for SA. Our aim was to synthesize the available evidence regarding the
influence of preprocedural pain duration on the outcome of vertebral augmentation procedures.

MATERIALS AND METHODS: The MEDLINE data base was reviewed up to March 2010. Meta-regression and mixed-effect subgroup analyses were performed to evaluate the association between the outcome of interest, which was pain improvement assessed by a VAS $(0-10)$ and the duration of preoperative pain (independent variable).

RESULTS: We included 17 articles. The mean VAS improvements for subgroups of $\leq 6$ weeks $(n=12)$, 6-24 weeks $(n=5)$, and $>24$ weeks $(n=3)$ were $5.18,4.90$, and 5.04 , respectively $(P=.86)$. The regression coefficient was -0.024 , suggesting trivial association of the duration of preoperative pain and pain improvement.

CONCLUSIONS: Pain relief following spine augmentation was similar among groups of patients with varying lengths of preoperative pain duration.

ABBREVIATIONS: $\mathrm{KP}=$ kyphoplasty; $\mathrm{NA}=$ not applicable; $\mathrm{SA}=$ spine augmentation; $\mathrm{VAS}=$ visual analog scale; $\mathrm{VP}=$ vertebroplasty
V ertebral augmentation is widely applied for the treatment of painful vertebral compression fractures, both benign and malignant. ${ }^{1-10}$ Specific clinical and imaging selection criteria include duration and pattern of subjective pain; imaging characteristics on plain film, MR imaging, and CT; and findings on physical examination. Among these selection criteria, duration of pain has garnered substantial interest. When initially applied, vertebral augmentation was reserved for patients who had failed at least 4-6 weeks of conservative therapy. This waiting period was recommended, given the knowledge that in most patients, spontaneous osteoporotic compression fractures will heal without intervention during several weeks.

With increasing clinical experience, the indications for vertebral augmentation have expanded to include patients with relatively acute fractures. Indeed, some practitioners suggest that these early fractures represent the ideal candidates for augmentation and that more chronic fractures are poor candidates for intervention. ${ }^{11-14}$

Several studies evaluated the impact of pain duration on the observed outcome following vertebral augmentation. ${ }^{15-17}$ Improved understanding of the impact of pain duration would help guide practitioners in selecting patients for augmentation. We conducted a systematic review and meta-analysis of the vertebral augmentation literature to synthesize the available evidence regarding the influence of preprocedural pain duration on the outcome of vertebral augmentation procedures.

From the Departments of Radiology (A.E., D.F.K.) and Preventive Medicine (M.H.M.), Mayo Clinic, Rochester, Minnesota; and College of Saint Benedict/Saint John's University (M.T.L.), St. Joseph, Minnesota.

Please address correspondence to Arash Ehteshami, MD, Department of Radiology, Mayo Clinic, 200 First St SW, Rochester, MN 55905; e-mail: arashehteshami@yahoo.com

http://dx.doi.org/10.3174/ajnr.A2618

\section{Materials and Methods}

A comprehensive review of the literature up to March 2010 was performed by 2 independent reviewers. "Vertebroplasty pain" and "kyphoplasty pain" were used as both controlled vocabulary and keywords to search MEDLINE by using the Ovid interface. The 2 reviewers discussed disagreements and reconciled their differences. The results were limited to case series, case-controlled studies, major clinical studies, clinical trials, and cohort studies. Inclusion criteria were the following: English language, $>50$ patients, numeric VAS assessment for pre- and postopertive pain, and availability of the mean age of fracture or preoperative pain duration. The exclusion criteria were the following: case reports, in vitro or cadaveric studies, guidelines and general discussions, and technical notes.

The electronic search was supplemented by asking experts in the field and reviewing the bibliographies of included studies for relevant publications. Abstracts, methods, results, figures, and tables of full text were searched for pain questions, pre- and postoperative numeric pain scales and preoperative pain duration, and/or vertebral fracture age at the time of vertebral augmentation. Preoperative pain duration and age of fracture were considered interchangeable, because few studies distinguished these. Pain improvement was calculated on the basis of the pre- and postprocedural VAS $(0-10)$ at 24 hours. Unfortunately, additional follow-up time points were incompletely reported among the identified studies.

To explore the impact of the mean duration of pain before intervention among studies, we grouped studies according to the mean preoperative pain duration ( $\leq 6$ weeks, $6-24$ weeks, and $>24$ weeks) and compared pain improvement among these. We also evaluated the correlation between the age of fracture and pain improvement by using a VAS.

Studies that were not adjustable to any of the above categorizations were excluded. From comparative studies between vertebral augmentation and conservative therapy or placebo control, only augmentation arms were included. All original preoperative pain lengths 

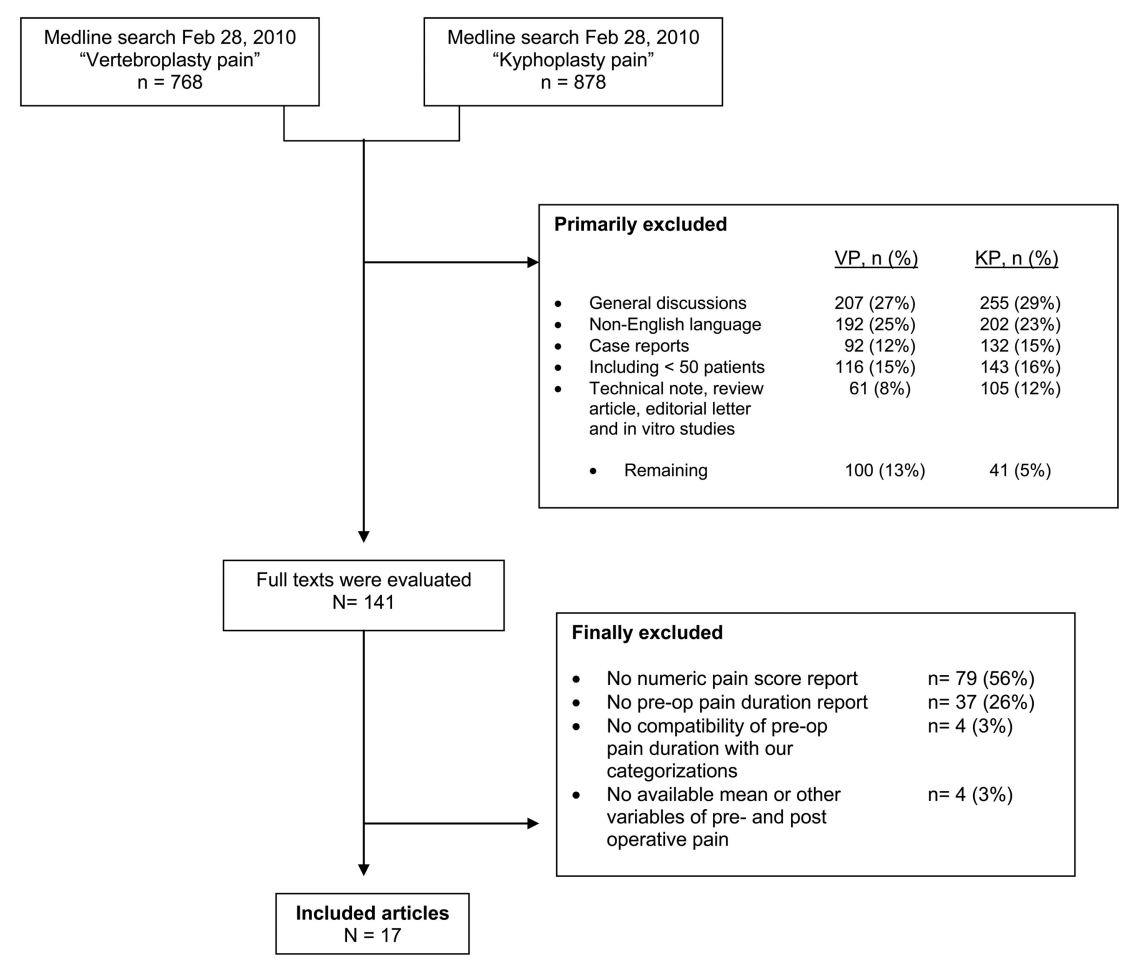

ncluded articles

Fig 1. Inclusion of the final 17 articles.

\begin{tabular}{|c|c|c|c|c|c|c|c|}
\hline \multirow[b]{2}{*}{ Authors } & \multirow[b]{2}{*}{ Study Design } & \multirow[b]{2}{*}{ SA Type } & \multirow[b]{2}{*}{$\begin{array}{c}\text { Patients } \\
\text { (levels) }\end{array}$} & \multicolumn{2}{|c|}{ Preoperative Pain } & \multirow[b]{2}{*}{$\begin{array}{l}\text { Postoperative } \\
\text { VAS }^{\mathrm{a}}\end{array}$} & \multirow[b]{2}{*}{$\begin{array}{l}\text { Level of } \\
\text { Evidence }\end{array}$} \\
\hline & & & & $\begin{array}{l}\text { Age of } \\
\text { Fracture }\end{array}$ & VAS & & \\
\hline \multirow[t]{2}{*}{$\overline{\text { Alvarez et al }}{ }^{1}$} & Prospective, double cohort & VP & $101(152)$ & 5 Months & 8.9 & 4.0 & 2 \\
\hline & & Conservative & $27(28)$ & 5.8 Months & 7.3 & 7.3 & \\
\hline Chen et $\mathrm{al}^{19}$ & Retrospective & VP & $70(87)$ & 8 Months & $80(0-100)$ & $38(0-100)$ & 4 \\
\hline \multirow[t]{2}{*}{ Diamond et $\mathrm{a}^{20}$} & Prospective, non-randomized & VP & $88(133)$ & 1-6 Weeks & $20(0-25)$ & $8(0-25)$ & 2 \\
\hline & & Conservative & 38 (NA) & 1-6 Weeks & $20(0-25)$ & $19(0-25)$ & \\
\hline Garfin et $\mathrm{al}^{21}$ & $\begin{array}{l}\text { Prospective single-arm } \\
\text { interventional cohort }\end{array}$ & $\mathrm{KP}$ & $155(214)$ & 128.5 Days & $15(0-20)$ & $5(0-20)$ & 4 \\
\hline \multirow[t]{2}{*}{ Kallmes et $a^{28}$} & $\begin{array}{l}\text { Randomized double-blinded } \\
\text { controlled trial }\end{array}$ & Placebo & $63(93)$ & 20 Weeks & 7.2 & 3.9 & 1 \\
\hline & & VP & $68(95)$ & 16 Weeks & 6.9 & 4.2 & \\
\hline Kobayashi et $\mathrm{al}^{29}$ & Prospective & VP & $175(250)$ & 19 Days & 7.2 & 2.1 & 4 \\
\hline Lee et $\mathrm{al}^{30}$ & Retrospective & $\mathrm{KP}$ & $105(132)$ & 4.5 Weeks & 8.7 & 2.3 & 4 \\
\hline \multirow[t]{2}{*}{ Liu et $\mathrm{al}^{31}$} & Randomized clinical trial & $\mathrm{KP}$ & $50(50)$ & 15.8 Days & 8.0 & 2.6 & 2 \\
\hline & & VP & $50(50)$ & 17 Days & 7.9 & 2.3 & \\
\hline Prather et al ${ }^{32}$ & Prospective & VP & $50(103)$ & 14 Months & 7.8 & 3.1 & 4 \\
\hline Rapan et $\mathrm{al}^{33}$ & NA & VP & $55(85)$ & 44 Days & 8.36 & 2.23 & 4 \\
\hline Rhyne et $\mathrm{al}^{25}$ & Retrospective & $\mathrm{KP}$ & $52(82)$ & 31 Weeks & 9.16 & 2.9 & 4 \\
\hline \multirow[t]{2}{*}{ Rolloinghoff et a $\left.\right|^{34}$} & Prospective & $\mathrm{KP}$ & $45(53)$ & 3 Weeks & 8.6 & 3.4 & 2 \\
\hline & & VP & $45(51)$ & 3 Weeks & 8.8 & 4.8 & \\
\hline \multirow[t]{2}{*}{ Rousing et $\mathrm{al}^{35}$} & Randomized clinical trial & Conservative & $24(32)$ & 6.7 Days & 8.8 & NA & 2 \\
\hline & & VP & $25(31)$ & 8.4 Days & 7.5 & 2.0 & \\
\hline \multirow[t]{2}{*}{ Schofer et $\mathrm{a}^{36}$} & Prospective & $\mathrm{KP}$ & $30(30)$ & 9.5 Days & 8.2 & 3.2 & 2 \\
\hline & & VP & $30(30)$ & 10.5 Days & 8.3 & 3.0 & \\
\hline Vogl et $\mathrm{al}^{26}$ & Retrospective & VP & 61 (NA) & 19 Days & 8.8 & 2.6 & 4 \\
\hline Voormolen et $\mathrm{al}^{9}$ & Prospective & VP & $112(168)$ & 4 Months & 8.8 & 3.3 & 4 \\
\hline \multirow[t]{2}{*}{ Wardlaw et $a^{31}$} & Randomized clinical trial & Conservative & 151 (195) & 6.4 Weeks & 7.0 & 5.9 & 2 \\
\hline & & $\mathrm{KP}$ & 149 (214) & 5.6 Weeks & 6.9 & 3.6 & \\
\hline
\end{tabular}

${ }^{a}$ Visual Analog Scale. 
Table 2: Demographics of categories with various preoperative pain durations ${ }^{\text {a }}$

\begin{tabular}{lccc}
\hline & $\leq 6$ Weeks $^{20,26,29-31,34-37}$ & $6-24$ Weeks $^{1,9,21,28,33}$ & $>24$ Weeks $^{19,25,32}$ \\
\hline No. of included studies & 12 & 5 & 3 \\
No. of patients (mean) (SD, range) & $71(49,25-175)$ & $98(39,55-155)$ & $57(11,50-70)$ \\
No. of levels (mean) (SD, range) & $93(78,30-250)$ & $143(53,85-214)$ & $91(11,82-103)$ \\
Preoperative pain duration by week (mean) (SD, range) & $2.7(1.3,1.2-5.6)$ & $15.9(5.7,6.3-21.5)$ & $42(16,31-60)$ \\
\hline
\end{tabular}

${ }^{a}$ The studies ${ }^{11,13,15}$ that did not present a single number for preoperative pain or age of fracture were excluded from this calculation.

\begin{tabular}{ll}
\hline Group by & Study name \\
\cline { 1 - 2 } Age of fracture & \\
& \\
$<6$ wks & $\begin{array}{c}\text { Dift } \\
\text { in }\end{array}$ \\
$<6$ wks & Kobayashi, 2005 \\
$<6$ wks & Wardlaw, 2009 \\
$<6$ wks & Lee SB, 2008 \\
$<6$ wks & Diamond, 2006 \\
$<6$ wks & Vogl, 2006 \\
$<6$ wks & Liü, 2010 \\
$<6$ wks & Liu, 2010 \\
$<6$ wks & Rollinghoff ${ }^{*}, 2009$ \\
$<6$ wks & Rollinghoff, 2009 \\
$<6$ wks & Schofer ${ }^{*}, 2009$ \\
$<6$ wks & Schofer, 2009 \\
$<6$ wks & Rousing, 2009 \\
$>24$ wks & \\
$>24$ wks & Chen, 2004 \\
$>24$ wks & Rhyne, 2004 \\
$>24$ wks & Prather, 2006 \\
$6-24$ wks & \\
$6-24$ wks & Garfin, 2006 \\
$6-24$ wks & Voormolen, 2006 \\
$6-24$ wks & Alvarez, 2006 \\
$6-24$ wks & Kallmes, 2009 \\
$6-24$ wks & Rapan, 2009 \\
Overall & \\
&
\end{tabular}

Statistics for each study $\begin{array}{cccc}\begin{array}{c}\text { Difference } \\ \text { in means }\end{array} & \begin{array}{c}\text { Standard } \\ \text { error }\end{array} & \begin{array}{c}\text { Lower } \\ \text { limit }\end{array} & \begin{array}{c}\text { Upper } \\ \text { limit }\end{array}\end{array}$ $\begin{array}{rrrr}5.10 & 0.17 & 4.77 & 5.43\end{array}$ $\begin{array}{llll}3.30 & 0.27 & 2.78 & 3.82\end{array}$ $\begin{array}{llll}6.40 & 0.16 & 6.08 & 6.72 \\ 4.80 & 0.24 & 4.33 & 5.27\end{array}$ $\begin{array}{llll}4.80 & 0.24 & 4.33 & 5.27 \\ 6.20 & 0.16 & 5.89 & 6.51\end{array}$ $\begin{array}{llll}5.40 & 0.14 & 5.89 & 6.51\end{array}$ $\begin{array}{llll}5.60 & 0.12 & 5.36 & 5.64\end{array}$ $\begin{array}{llll}5.20 & 0.44 & 4.33 & 6.07\end{array}$ $\begin{array}{llll}4.00 & 0.41 & 3.19 & 4.81\end{array}$ $\begin{array}{llll}5.00 & 0.47 & 4.07 & 5.93\end{array}$ $\begin{array}{lllll}5.30 & 0.56 & 4.21 & 6.39\end{array}$ $\begin{array}{llll}5.70 & 0.77 & 4.19 & 7.21\end{array}$ $\begin{array}{llll}5.17 & 0.26 & 4.66 & 5.21\end{array}$ $\begin{array}{llll}4.20 & 0.34 & 3.52 & 4.88\end{array}$ $\begin{array}{llll}6.26 & 0.44 & 5.41 & 7.11\end{array}$ $\begin{array}{llll}4.70 & 0.51 & 3.69 & 5.71\end{array}$ $\begin{array}{llll}5.04 & 0.55 & 3.97 & 6.11\end{array}$ $\begin{array}{llll}5.00 & 0.29 & 4.42 & 5.58\end{array}$ $\begin{array}{llll}5.50 & 0.31 & 4.90 & 6.58\end{array}$ $\begin{array}{llll}5.50 & 0.31 & 4.90 & 0.10\end{array}$ $\begin{array}{llll}2.70 & 0.48 & 3.98 & 5.84\end{array}$ $\begin{array}{llll}6.13 & 0.16 & 5.81 & 6.45\end{array}$ $\begin{array}{llll}4.91 & 0.41 & 4.11 & 5.71\end{array}$ $\begin{array}{llll}5.09 & 0.20 & 4.69 & 5.49\end{array}$
Difference in means and $95 \% \mathrm{Cl}$

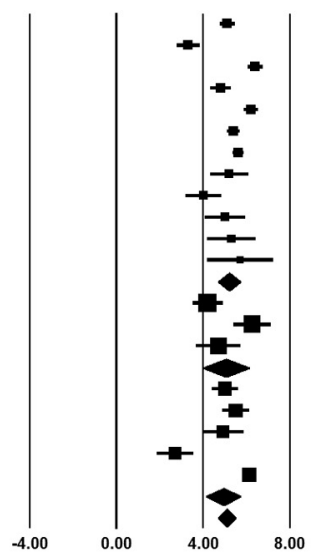

Pain improvement

Meta Analysis

Fig 2. The forest plot shows subgroup analysis.

were converted to weeks, and numeric pain scores other than $0-10^{18-22}$ were converted to $0-10$ scores.

\section{Statistical Analysis}

Statistical analysis was performed by using Comprehensive MetaAnalysis, Version 2 software (Biostat, Englewood, New Jersey). Continuous data, including mean pain improvement on the VAS, were pooled to calculate weighted mean differences with $95 \%$ confidence intervals. A random-effects model was used ${ }^{23}$; subgroups were compared by using the $Z$-test. The null hypothesis was that the effect size was the same for all subgroups. $\mathrm{I}^{2}$ was used to assess heterogeneity across studies. ${ }^{24}$ The influence of sample size was assessed by funnel plots and the trim-and-fill method, and the presence of publication bias was assessed by the Egger regression test. A random-effects metaregression was used to assess the preoperative pain duration covariate with pain improvement as a dependent variable. Publication bias was assessed by using the trim-and-fill model. We excluded 1 study ${ }^{20}$ because preoperative pain was reported only as a range ( $<6$ weeks) without a mean. SDs for 3 studies ${ }^{9,25,26}$ were calculated through other formulas. ${ }^{27}$ Sensitivity analysis was performed by excluding every single study from the analysis to assess the robustness of final assumptions and by conducting a cumulative meta-analysis to explore how pre- and postoperative mean pain differences varied with increasing preoperative pain duration.

\section{Results}

Between July 1985 and March, 2010, 768 articles were retrieved by using the term "vertebroplasty pain" and 878 articles were found by using the term "kyphoplasty pain." Fig 1 details the study-selection processes and the reasons for exclu- sion. The final cohort included 17 studies $^{1,9,19-21,25,26,28-37}$ described in Table 1. Among these included studies, 6 (35\%) reported age of fracture, ${ }^{21,28,29,32,35,37} 13$ (76\%) described preoperative pain duration, ${ }^{1,9,19,20,25,26,28,30,31,33,34,36,37}$ and 2 $(12 \%)$ stated both. ${ }^{28,37}$

There were $3(18 \%)$ articles that compared vertebroplasty with kyphoplasty, ${ }^{31,34,36} 4(24 \%)$ compared vertebroplasty with conservative therapy, ${ }^{1,20,28,35}$ and 1 (6\%) compared kyphoplasty with conservative therapy. ${ }^{37}$ Six $(35 \%)^{9,19,26,29,32,33}$ of 17 articles included exclusively vertebroplasty procedures, while 3 (18\%) studies reported kyphoplasty procedures exclusively. ${ }^{21,25,30}$ We included 1516 patients and 2010 treated levels through 20 treatment arms of 17 studies. The mean $( \pm$ SD) number of patients and levels was 76 (43.8) and 106 (67.6), respectively, per study. The median follow-up was 12 months (range, 3-24 months). ${ }^{21,33,35}$ The characteristics of each subgroup are shown in Table 2.

For the meta-analysis, the Q-statistic was 0.311 with $d f=2$ and $P=.86$ (Fig 2). Thus, we cannot reject the null hypothesis that the effect size is the same for all 3 groups (Table 3 ).

With the random-effects model, the raw mean difference (pain improvement) for 19 studies was 5.10 VAS with a confidence interval of $4.70-5.50$, which yields a $Z$ value of 24.860 (2-tailed $P<.001)$. Because of the weak correlation, the null hypothesis of no linear relation between the length of pain and pain improvement was rejected.

Within-group heterogeneity expressed by using the $\mathrm{I}^{2}$ statistic was quite high: $92.61 \%, 93.81 \%$, and $95.74 \%$ for studies with $<6$ weeks', 6-24 weeks', and $>24$ weeks' preoperative pain. The regression coefficient for preoperative pain duration 


\begin{tabular}{lccccccc}
\hline \multicolumn{2}{l}{ Table 3: Details of meta-analysis under the random-effects model } \\
\multicolumn{1}{l}{$\begin{array}{c}\text { Point } \\
\text { Estimate }\end{array}$} & $\begin{array}{c}\text { Standard } \\
\text { Error }\end{array}$ & Variance & Lower & Upper & \\
Limit & Limit & $Z$ value & $P$ value \\
\hline$\leq 6$ Weeks & 5.18 & 0.263 & 0.069 & 4.66 & 5.70 & 19.683 & $<.001$ \\
$6-24$ Weeks & 4.90 & 0.406 & 0.165 & 4.11 & 5.70 & 12.081 & $<.001$ \\
$>24$ Weeks & 5.04 & 0.547 & 0.299 & 3.97 & 6.11 & 6.110 & $<.001$ \\
\hline
\end{tabular}

Regression of Age of fracture by weeks on Difference in means

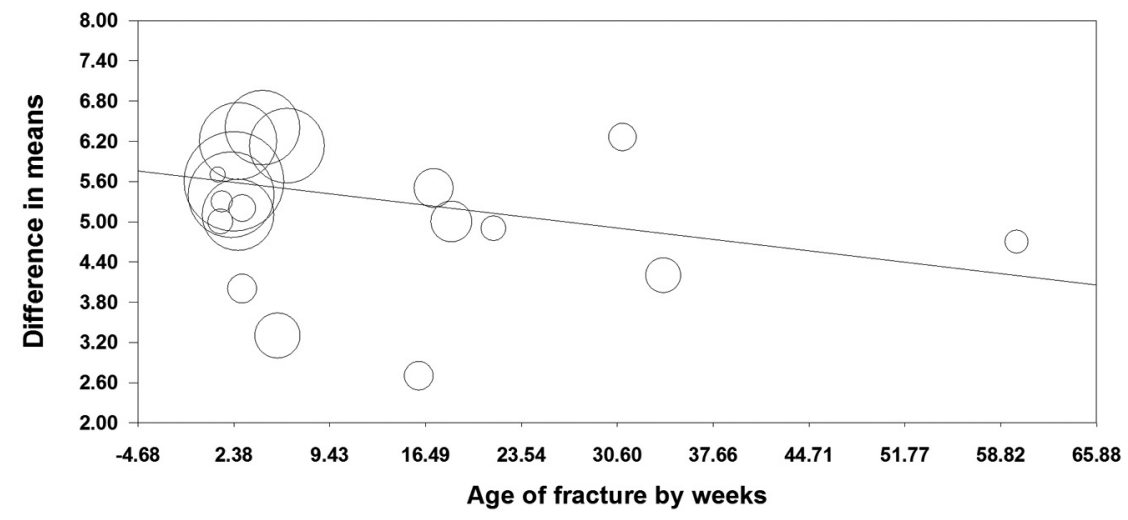

Fig 3. The linear correlation between preoperative pain duration and pain improvement is shown.

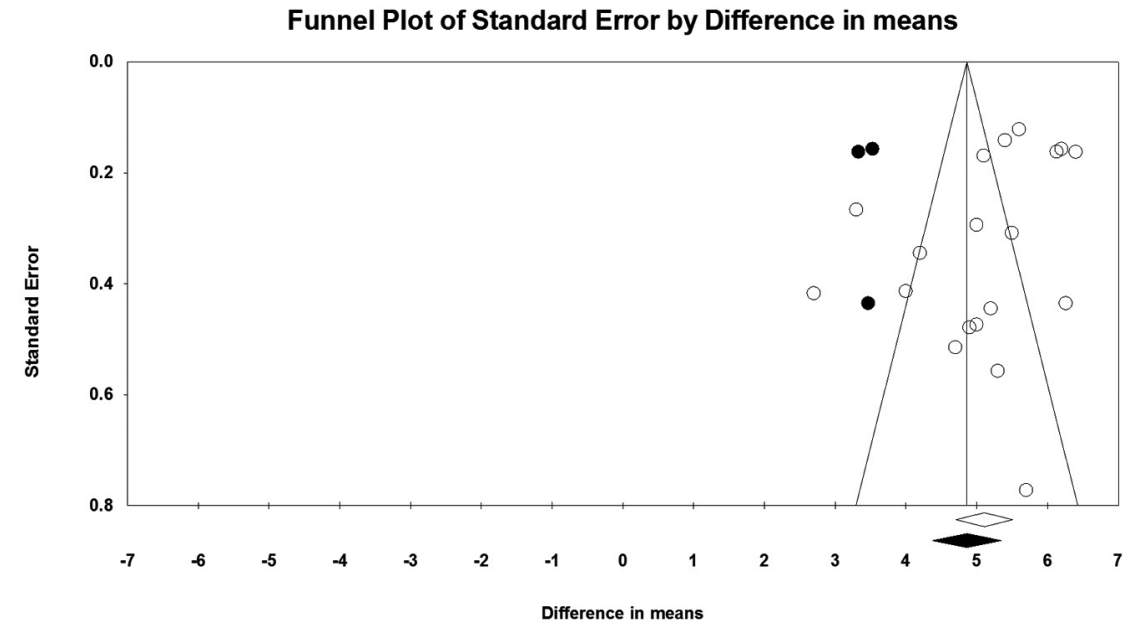

Fig 4. Publication bias among studies is shown.

was -0.024 , which indicates that for each 1-week increase in the length of preoperative pain, the VAS in pain improvement decreased by 0.024 (Fig 3). The model and residual $Q$ were 16.43 and 208.23, respectively. The clinical significance of this trivial correlation is unclear. There were 3 missing studies on the left of the mean in the funnel plot (Fig 4). Adjusted mean pain improvement was $4.9(4.4-5.3)$ and $\mathrm{Q}=510.9$. The cumulative meta-analysis shows how increase in the age of fracture from the shortest preoperative pain duration ${ }^{35}$ to the longest one ${ }^{32}$ shifts pain improvement among studies (Fig 5).

The impact of sample size is shown in cumulative metaanalysis from the biggest sample size study ${ }^{29}$ to the smallest one (Fig 6). ${ }^{35}$ The Egger regression test for publication bias was significant $(P=.03)$, suggesting the presence of publication bias.

In sensitivity analysis, the final outcome did not depend on any single study result.

\section{Discussion}

We conducted a meta-analysis that showed that vertebral augmentation is associated with significant reduction in back pain. However, we did not find any significant difference in pain improvement among subgroups with different preoperative pain durations. There was also a weak negative correlation between the age of fracture and immediate pain improvement after vertebral augmentation. The clinical significance of this slight correlation remains unclear. Thus, it seems that the age of fracture does not affect the outcome of vertebral augmentation; therefore, a wider range of patients could be referred for the procedure.

One prior study has shown that early treatment was correlated with greater patient satisfaction with the outcome. Unfortunately, the metric of "satisfaction with care" is rarely reported in the spine-augmentation literature. Future studies should include this specific outcome. ${ }^{38}$ 


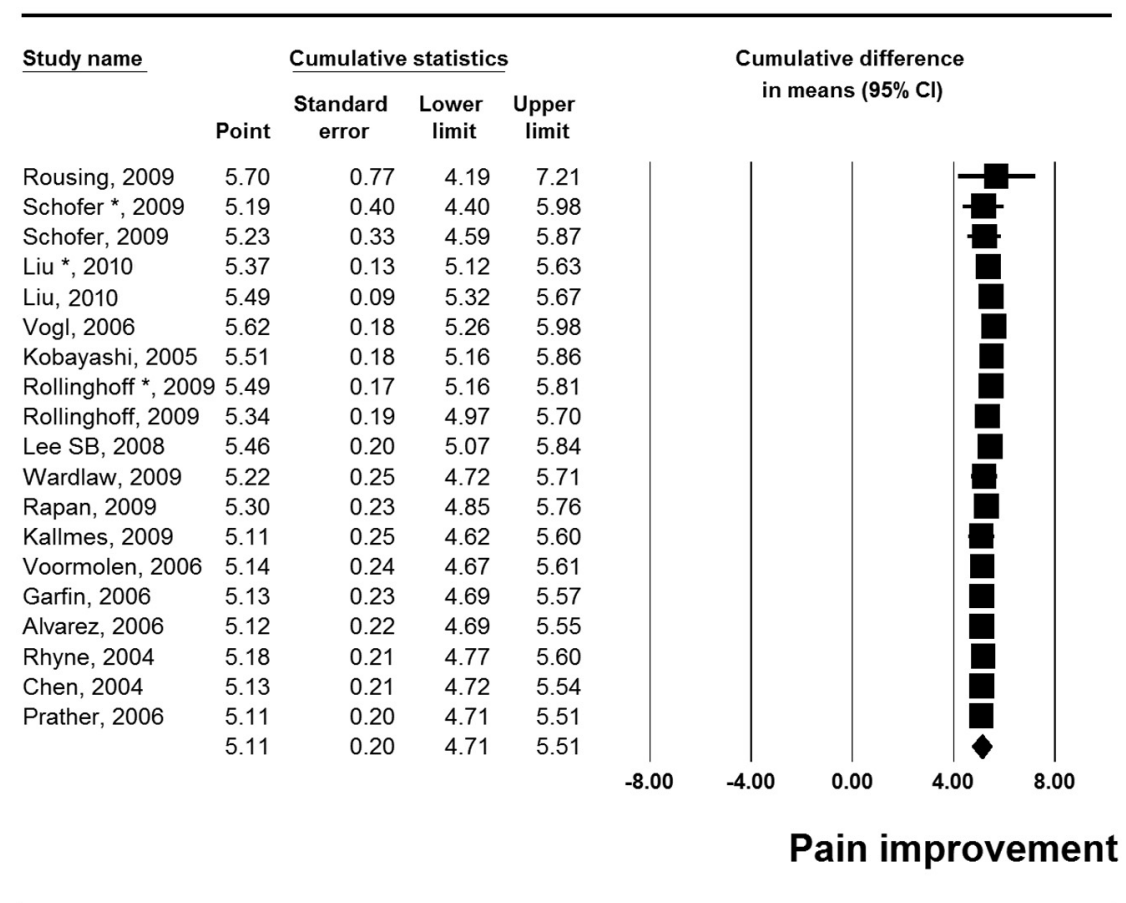

Meta Analysis

Fig 5. The cumulative meta-analysis shows the influence of increasing preoperative pain duration on the outcome of the study.

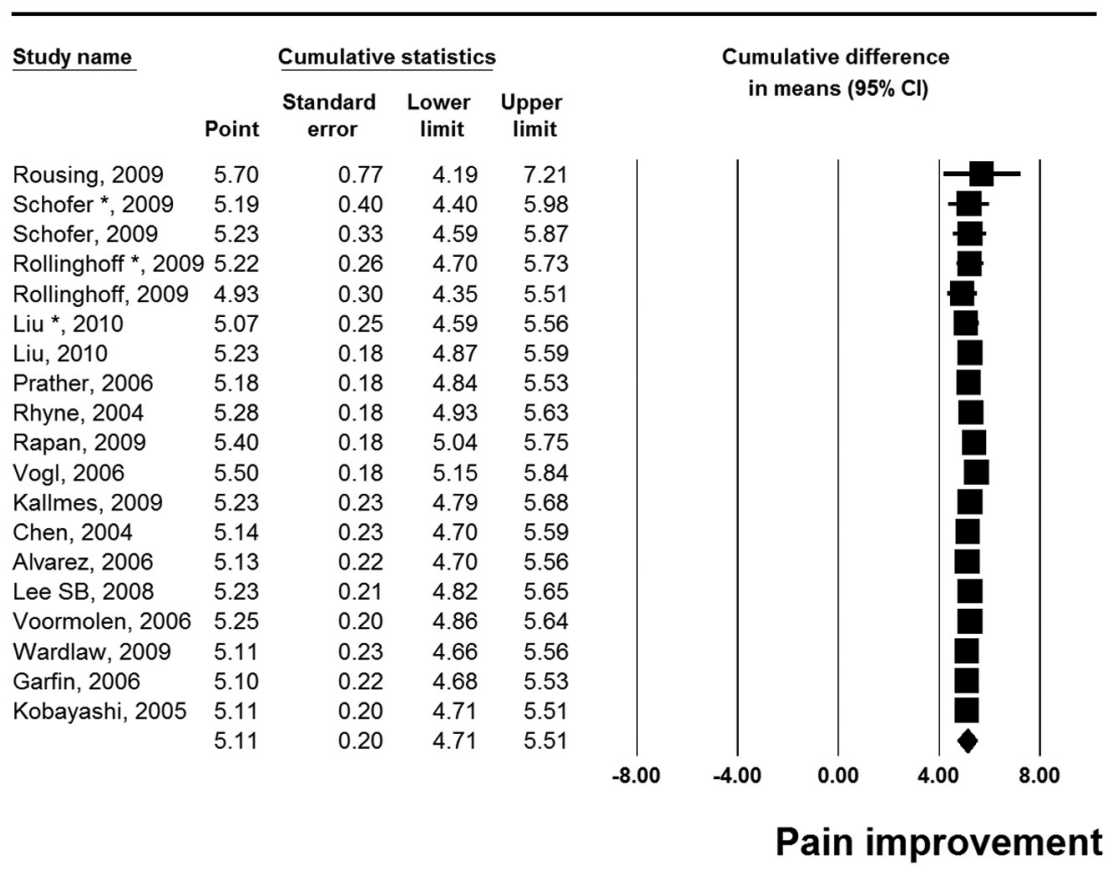

Meta Analysis

Fig 6. The cumulative meta-analysis shows the influence of increasing sample size on the outcome of the study.

Treatment of acute fractures might seem to be the ideal paradigm because pain in these fractures may be maximal. However, the few controlled studies currently available regarding acute fracture treatment have shown identical outcomes between patients treated with augmentation versus those treated conservatively. ${ }^{20,35}$ The noted similar improvements between groups in those studies may relate to the nat- ural history of vertebral fracture pain, which shows substantial improvement in the conservatively managed patient groups.

The limitations of this study mainly relate to ecologic bias (ie, comparisons are made across studies and not within studies), the presence of publication bias and statistical heterogeneity, and the methodologic limitations of the included studies (lack of random allocation, small sample size, and 
incomplete baseline and follow-up data). Another limitation relates to the inclusion of only English language literature. However, we attempted to minimize this limitation by asking experts in the field about relevant studies to complement our search strategy.

\section{Conclusions}

Pain relief following SA was similar among groups of patients with varying lengths of preoperative pain duration.

Disclosures: David Kallmes. Research Support (including provision of equipment or materials): Cook, ArthroCare, CareFusion, Stryker; Details: research support; Consultant: CareFusion; Details: preparation of education materials.

\section{References}

1. Alvarez L, Alcaraz M, Perez-Higueras A, et al. Percutaneous vertebroplasty: functional improvement in patients with osteoporotic compression fractures. Spine 2006;31:1113-18

2. Anselmetti GC, Corrao G, Monica PD, et al. Pain relief following percutaneous vertebroplasty: results of a series of 283 consecutive patients treated in a single institution. Cardiovasc Intervent Radiol 2007;30:441-47

3. Jha RM, Yoo AJ, Hirsch AE, et al. Predictors of successful palliation of compression fractures with vertebral augmentation: single-center experience of 525 cases. J Vasc Interv Radiol 2009;20:760-68

4. Layton KF, Thielen KR, Koch CA, et al. Vertebroplasty, first 1000 levels of a single center: evaluation of the outcomes and complications. AJNR Am J Neuroradiol 2007;28:683-89

5. Masala S, Mastrangeli R, Petrella MC, et al. Percutaneous vertebroplasty in 1,253 levels: results and long-term effectiveness in a single centre. Eur Radiol 2009;19:165-71

6. Mathis JM, Barr JD, Belkoff SM, et al. Percutaneous vertebroplasty: a developing standard of care for vertebral compression fractures. AJNR Am J Neuroradiol 2001;22:373-81

7. McGraw JK, Lippert JA, Minkus KD, et al. Prospective evaluation of pain relief in 100 patients undergoing percutaneous vertebroplasty: results and followup. J Vasc Interv Radiol 2002;13:883-86

8. Peh WC, Gilula LA, Peck DD. Percutaneous vertebroplasty for severe osteoporotic vertebral body compression fractures. Radiology 2002;223:121-26

9. Voormolen MH, Lohle PN, Lampmann LE, et al. Prospective clinical follow-up after percutaneous vertebroplasty in patients with painful osteoporotic vertebral compression fractures. J Vasc Interv Radiol 2006;17:1313-20

10. Zoarski GH, Snow P, Olan WJ, et al. Percutaneous vertebroplasty for osteoporotic compression fractures: quantitative prospective evaluation of long-term outcomes. J Vasc Interv Radiol 2002;13:139-48

11. Barr JD, Barr MS, Lemley TJ, et al. Percutaneous vertebroplasty for pain relief and spinal stabilization. Spine 2000;25:923-28

12. McGraw JK, Cardella J, Barr JD, et al. Society of Interventional Radiology quality improvement guidelines for percutaneous vertebroplasty. J Vasc Interv Radiol 2003;14:S311-S315

13. Nussbaum DA, Gailloud P, Murphy K. A review of complications associated with vertebroplasty and kyphoplasty as reported to the Food and Drug Administration medical device related web site. J Vasc Interv Radiol 2004;15: 1185-92

14. Peh WC, Gilula LA. Percutaneous vertebroplasty: Indications, contraindications, and technique. Br J Radiol 2003;76:69-75

15. Alvarez L, Perez-Higueras A, Granizo JJ, et al. Predictors of outcomes of percutaneous vertebroplasty for osteoporotic vertebral fractures. Spine 2005;30: $87-92$

16. Erkan S, Ozalp TR, Yercan HS, et al. Does timing matter in performing ky- phoplasty? Acute versus chronic compression fractures. Acta Orthop Belg 2009;75:396-404

17. Kaufmann TJ, Jensen ME, Schweickert PA, et al. Age of fracture and clinical outcomes of percutaneous vertebroplasty. AJNR Am J Neuroradiol 2001;22: $1860-63$

18. Atalay B, Caner H, Gokce C, et al. Kyphoplasty: 2 years of experience in a neurosurgery department. Surg Neurol 2005;64(suppl 2):S72-76

19. Chen LH, Niu CC, Yu SW, et al. Minimally invasive treatment of osteoporotic vertebral compression fracture. Chang Gung Med J 2004;27:261-67

20. Diamond $\mathrm{TH}$, Bryant $\mathrm{C}$, Browne $\mathrm{L}$, et al. Clinical outcomes after acute osteoporotic vertebral fractures: a 2-year non-randomised trial comparing percutaneous vertebroplasty with conservative therapy. Med J Aust 2006;184: $113-17$

21. Garfin SR, Buckley RA, Ledlie J. Balloon kyphoplasty for symptomatic vertebral body compression fractures results in rapid, significant, and sustained improvements in back pain, function, and quality of life for elderly patients. Spine (Phila Pa 1976) 2006;31:2213-20

22. Wiggins MC, Sehizadeh M, Pilgram TK, et al. Importance of intravertebral fracture clefts in vertebroplasty outcome. AJR Am J Roentgenol 2007;188: $634-40$

23. DerSimonian R, Laird N. Meta-analysis in clinical trials. Control Clin Trials 1986;7:177-88

24. Higgins J, Thompson S, Deeks J, et al. Measuring inconsistency in meta-analyses. BMJ 2003;327:557-60

25. Rhyne A 3rd, Banit D, Laxer E, et al. Kyphoplasty: report of eighty-two thoracolumbar osteoporotic vertebral fractures. J Orthop Trauma 2004;18:294-99

26. Vogl TJ, Proschek D, Schwarz W, et al. CT-guided percutaneous vertebroplasty in the therapy of vertebral compression fractures. Eur Radiol 2006;16:797-803

27. Hozo SP, Djulbegovic B, Hozo I. Estimating the mean and variance from the median, range, and the size of a sample. BMC Med Res Methodol 2005;5:13

28. Kallmes DF, Comstock BA, Heagerty PJ, et al. A randomized trial of vertebroplasty for osteoporotic spinal fractures. N Engl J Med 2009;361:569-79

29. Kobayashi K, Shimoyama K, Nakamura K, et al. Percutaneous vertebroplasty immediately relieves pain of osteoporotic vertebral compression fractures and prevents prolonged immobilization of patients. Eur Radiol 2005;15: 360-67

30. Lee SB, Cho KS, Huh PW, et al. Clinical and radiographic results of unilateral transpedicular balloon kyphoplasty for the treatment of osteoporotic vertebral compression fractures. Acta Neurochir Suppl 2008;101:157-60

31. Liu JT, Liao WJ, Tan WC, et al. Balloon kyphoplasty versus vertebroplasty for treatment of osteoporotic vertebral compression fracture: a prospective, comparative, and randomized clinical study. Osteoporos Int 2010; 21:359-64. Epub 2009 Jun 10

32. Prather H, Van Dillen L, Metzler JP, et al. Prospective measurement of function and pain in patients with non-neoplastic compression fractures treated with vertebroplasty. J Bone Joint Surg Am 2006;88:334-41

33. Rapan S, Jovanovic S, Gulan G. Vertebroplasty for vertebral compression fracture. Coll Antropol 2009;33:911-14

34. Rollinghoff M, Siewe J, Zarghooni $\mathrm{K}$, et al. Effectiveness, security and height restoration on fresh compression fractures: a comparative prospective study of vertebroplasty and kyphoplasty. Minim Invasive Neurosurg 2009;52:233-37. Epub 2010 Jan 14

35. Rousing R, Andersen MO, Jespersen SM, et al. Percutaneous vertebroplasty compared to conservative treatment in patients with painful acute or subacute osteoporotic vertebral fractures: three-months follow-up in a clinical randomized study. Spine (Phila Pa 1976) 2009;34:1349-54

36. Schofer MD, Efe T, Timmesfeld N, et al. Comparison of kyphoplasty and vertebroplasty in the treatment of fresh vertebral compression fractures. Arch Orthop Trauma Surg 2009;129:1391-99

37. Wardlaw D, Cummings SR, Van Meirhaeghe J, et al. Efficacy and safety of balloon kyphoplasty compared with non-surgical care for vertebral compression fracture (free): a randomised controlled trial. Lancet 2009;373:1016-24

38. Ryu KS, Park CK. The prognostic factors influencing on the therapeutic effect of percutaneous vertebroplasty in treating osteoporotic vertebral compression fractures. J Korean Neurosurg Soc 2009;45:16-23. Epub 2009 Jan 31 